\title{
Magicians at Work: Modelers as Institutional Entrepreneurs in the Global Governance of Agriculture and Food Security
}

\author{
Lise Cornilleau \\ Laboratoire Interdisciplinaire Sciences Innovations Sociétés, Paris-Est University \& Centre de Sociologie des \\ Organisations, Sciences Po, France/ lise.cornilleau@sciencespo.fr
}

\begin{abstract}
Global models of agriculture act as the epistemic basis for quantitative foresight, which guides international policymaking and research on agriculture. With the new political sociology of science as a backdrop, this article studies the actors who develop and use these models through the lens of field theory. Contributing to the dialogue between the neo-institutionalist field theory and its Bourdieusian version, it describes the structure and the dynamics of the strategic action field of modelling organizations, using the Bourdieusian notions of 'succession' and 'subversion' to refine the characterization of challengers. It also discusses the insights of the Bourdieusian concept of 'homology' to analyse the relations between the field of model producers and the field of model users. Whereas Bourdieu provides a primarily descriptive account of homologies, which are close to a "social magic without magicians" for Roueff, the present text describes magicians doing the work of producing homologies. Some modelers use intercomparison to reduce competition and to have their models used in the field of global governance, thus strategically producing homologies, while resolving the main modelling conflict of the field. These actors benefit from the recent evolution of the modelling field under the influence of climate change, to behave as what Fligstein and McAdam have called 'institutional entrepreneurs'. The article concludes that field theory makes it possible to describe the co-construction of a range of models developed by competing organizations and the controversial making of global agricultural governance. Doing so, it complements the co-production framework, which often focuses on a given site of expertise production and a site of global governance.
\end{abstract}

Keywords: field theory, global modelling, intercomparison, agriculture, climate change

\section{Introduction}

The 2008 economic and financial crisis shook the agricultural sector. A sudden rise in global agricultural prices (mainly grains) and massive acquisition of farmland by foreign investors hit several developing countries, and fanned the flames of political disputes in the so-called Arab Spring. This crisis reminded us of the vulnerability of agro-food systems that have become globalized. 
Climate change and the financialization of agricultural markets creates concerns that resource pressures, and resulting episodes of agricultural and food price volatility, would become more frequent. In this troubled context, economic models of world agriculture are the primary knowledge tools that decision-makers use to reflect on the future of agriculture and to arbitrate between policy options at an international scale. The accuracy of these models is under scrutiny by experts from the Food and Agriculture Organizations of the United Nations (FAO), the World Bank, the International Food Policy Research Institute (IFPRI) - a research institute in economics part of the Consultative Group in International Agricultural Research (CGIAR) - and more broadly within the academic field of agricultural economics, dominated by American, European, and Chinese universities. The 2008 crisis questions the way these models are elaborated and evaluated, and by whom. Yet, if the role of models in the global governance of agriculture is crucial, they have received less focus than in the cases of finance (McKenzie, 2006) or climate change (Dahan, 2007).

The co-production framework (Jasanoff, 2004) helps to understand the politics of models. Models are 'mediators' between theory and the real system (Morgan and Morrison, 1999). They stabilize a state of the art on a given topic in order to build prospective scenarios, which are increasingly used by decision-makers in a normative fashion. Based on a specific set of knowledge and assumptions, they contribute to 'perform' public policies in a specific way (Armatte, 2010; Henriksen, 2013). Previous work has shown how models of world agriculture based in neoclassical theory lay the groundwork for scenarios which offer a limited set of options for the future. As small-scale agriculture is 'invisibilized' in such models (Leblond and Trottier, 2016), the scenarios they enable to develop tend to promote technology-intensive agriculture over agroecology, and free-trade over food sovereignty (Fouilleux, 2010; Cornilleau, 2016). Hence, economic models represent certain 'worlds' that they help perform through scenario building. But why are certain models deemed more legitimate than others? What are the mechanisms of the competition between different models of a given problem, such as world agriculture?

In line with the new political sociology of science, I seek to complement the co-production framework by stressing the "unequal distributions of power and resources" (Frickel and Moore, 2006: 10) in modelling activity. The co-production perspective, by paying symmetrical attention to the "dominant point of view" and the "marginalized alternatives" (Jasanoff, 2004: 280), has already worked in this direction. Research inspired by Desrosières (2008) has analysed the production and use of alternative statistics, using the concept of 'statactivism' (Bruno et al., 2014; Kurunmäki et al, 2016). An actor-network theory approach (Callon, 1986) has highlighted the drivers of the success of a model, defined as its ability to enrol users at an early stage of scenario development (Kieken, 2004). These studies focus respectively on the attempts to create alternative quantifications (i.e. the "marginalized alternatives"), or on the modalities of a success (i.e. the "dominant point of view"). In this article, I use a complementary perspective to document inequalities in modelling activity. My goal is to map the field of modelling organizations (research institutes, international organizations, ministries of agriculture), and to enlighten how world agricultural models are being hierarchized. Inspired by previous research on metrics (Paradeise and Filliatreau, 2016), I use neo-institutionalist field theory (Fligstein and McAdam, 2012) while borrowing some concepts to Bourdieu (2015). If these perspectives rely on different hypotheses (Martin, 2003), the former was inspired by the latter. In both cases, a field is defined as a socially structured space of positions, organized through a struggle over what is specifically at stake in the field.

As the results of the modelled foresight are intended to circulate among experts and decision-makers, competition between models cannot be analysed only at the level of modelling organizations themselves. Models are part of the toolbox that States and stakeholders (companies, NGOs, modelling organizations themselves) use to influence the making of the global governance of agriculture. The introduction of 'good practices' (Bernstein and Van der Ven, 2017) encourages stakeholders to use quantified indicators in 
advocacy and lobbying strategies, which explains the increased competition between indicators of world problems (Rottenburg et al., 2015), as in the case of women's rights (Merry, 2016). Field theory accounts both for the dynamics in a given social space, and for the interactions with other social spheres: the modelling field can be analysed per se, and in interaction with the academic field or the field of global governance. This is different from the ecology of knowledge (Akera, 2007), which describes how forms of knowledge co-produce institutional hierarchies, yet does not address the dynamics within science and within society. Field theory is also more appropriate to analyse the competition between models than a market-based approach, which has been used on standards (Reinecke et al., 2012; Fouilleux, Loconto, 2017). World agricultural models interact with economic stakes', but they are mostly evaluated in scientific (they are deemed credible) or political (they are deemed legitimate) terms. A last advantage of field theory is its potential to illuminate the international dimension of the modelling field. Sociologists (Bigo, 2011, Go and Krause, 2016) stress that the internationalization of a field is non-linear, and that interactions with national stakes are decisive.

A field exists only if the space of interactions structures actors' behaviour to such an extent that it becomes a relevant level for analysis. Semistructured interviews with modelers showed that they situated their models in relation to others, and their representation of this space shaped the way they evaluated their own tools. Interviews gave insight into the topologies of the field: actors define the boundaries and the structure of the social space they moved within, and they describe their efforts to improve their position within it. In order to get a sense of what is at stake at the international level of this field, I conducted interviews both with representatives of national (French) and international modelling organizations. To map the positions of each modelling organization, and to track the circulation of models in governance and expertise, I analysed reports and minutes from an international research group - the Global Economics Team of the Agricultural Models Intercomparison and Improvement Project (AgMIP). This gave me access to debates amongst modelers about the evaluation and expected uses of their tools. The Global Economics Team of the AgMIP initially (2011-2013) included modelers from international organizations and US, Australian, Japanese, German, and Dutch research organizations, with ten models represented ${ }^{2}$, while the French modelling team joined the exercise in its second phase.

My argument has a three-part structure. In the first section, I show that the field of global agricultural models is not autonomous: its evolution is in sync with the 'climatisation' (Aykut et al.., 2017) of agricultural policies and research, i.e. the political demand that they take climate change into account. I describe how this 'climatisation' incites newcomers to enter the modelling field and how they tried to challenge the incumbent models. In the second section, the homologies between the field of model producers and the field of model users (including modelling organizations themselves) are highlighted: using a credible and legitimate model has direct effects on the position that institutions hold in the field of global governance. Last, I seek to explain the mechanisms standing behind these homologies, which are close to a "social magic without magicians" in Bourdieu's theory (Roueff, 2013). However, there are magicians here, and they play a central role. This last section shows these magicians at work: modelers who benefit from the recent evolution of the field and behave as 'institutional entrepreneurs' (Fligstein and McAdam, 2012). They use intercomparison within the AgMIP to reduce competition between models and to facilitate the circulation of their own models in the political field, thus producing homologies between the two fields, while solving the main conflict in the modelling field. I conclude that this amended field theory is a complement to the co-production framework, which has analysed jointly a given site of expertise and a site of global governance.

\section{The 'climatisation' of the field of global agricultural models}

This section presents recent shifts in the field of global agricultural models. It has changed under the imperative to integrate climate change. This 'climatisation' of the modelling field went hand 
in hand with a change in its structure. A conflict emerged between two different traditions: the equilibrium models' tradition focused on the economy was challenged by the integrated models' tradition, which better represented the links between the economy and climate change.

\section{From trade to climate: Models and the inter- national agenda of agriculture}

For Bourdieu, as well as for Fligstein and McAdam, a field is only partially autonomous from other fields, and inter-field relationships influence the structure and dynamics of a given field. Fligstein and McAdam (2012) think of inter-field relationships in terms of their embeddedness within each other ${ }^{3}$, from the macro level (e. g. the global governance field) to the micro level (e. g. an office in the department of a State), and compare fields to 'Russian dolls's. The modelling field is not autonomous from the global governance field, and can be considered as one of its subfields. Global agricultural models have changed in accordance with shifts in international agricultural policies; they initially focused on the trade agenda and on the preparation of a 'Doubly Green Revolution' (Cornilleau and Joly, 2014), only to change their orientation when climate change became a priority.

The trade agenda determined the first shift in economic agricultural models. In the 1970s, two categories of economic models coexisted: (i) time series models, which describe the dynamics of physical aggregates over time, whereas the (ii) first equilibrium models, which compute prices by balancing global supply and demand, appeared in the context of the 1974 world food crisis (Cornilleau, 2016). At the end of the 1970s, economists from agro-exporter countries (mostly from the United States of America (USA)), from the Organization for Economic Cooperation and Development (OECD) and from the IFPRI questioned the ability of time series models to simulate the impacts of trade policies on domestic agricultural prices. The reason for this was that agricultural trade liberalization was under examination in these countries and organizations, before the first steps of its implementation were negotiated at the Uruguay Round (1986-1994) of the General Agreement on Tariffs and Trade (GATT).
Equilibrium models ${ }^{5}$ ended up mediating controversies on trade, notably on the level of agricultural subsidies in the USA versus in the European Economic Community in the 1980s (Fouilleux, 2000). American universities and research institutes played a leading role in the development of these equilibrium models. The US Department of Agriculture and the Ford Foundation funded the International Agricultural Trade Research Center (IATRC), a think tank whose goal was to equip the OECD and the GATT negotiations with the economic toolkit that delegitimized subsidies and led to trade liberalization in agriculture (Joly and Lacombe, 2017). The US also supported networks of modelers working on the development of an international agricultural database, such as the Global Trade Analysis Project (GTAP) created in 1991 at the Purdue University in interaction with the FAO and the OECD (Leblond and Trottier, 2016; Dorin and Joly, 2019), which is still widely used today. In the 1990s, equilibrium models were developed by other institutions for different purposes, such as the IFPRI with the International Model for Policy Analysis of Agricultural Commodities and Trade (IMPACT) in 1995. This model became a flagship for the IFPRI, which supported foresight aiming at funding international agricultural research around the project of a "doubly Green Revolution", thanks to its format emphasizing the promises of technologies (Cornilleau, 2016). This brief genealogy ${ }^{6}$ shows how economic models are both tools of proof and tools of power to defend national, or institutional, interests in the making of international agricultural policies.

The field of global agricultural models underwent another major change, which is at the heart of this article. Agricultural models have received renewed attention since the 4th report of the Intergovernmental Panel on Climate Change (IPCC) concluded in 2007 that agriculture is both a major driver of climate change and an area particularly affected by it, with worrying impacts on food security. Decision-makers now expect models to allow them to reflect on the interactions between agriculture, food, energy, and the environment. The 'climatisation' of the agricultural agenda had a counterpart in the 'climatisation' of the modelling field, which is twofold. First, equilibrium models seek to better represent the 
environment and climate change by relying on agroecological zones instead of political divides (such as countries or regions) and they tend to adopt a modular structure (what enables them to add modules representing the environment). Second, integrated models, another modelling tradition ${ }^{7}$ grounded in the Club of Rome perspective focused on the interactions between human activities and the environment, were increasingly seen as more credible to represent the environment than equilibrium models, which conceive of agriculture as an industrial sector. This was all the more the case that in the 2000s, integrated models sought to provide more details on the equilibrium of the economy, hence undermining equilibrium models' added value. These evolutions ${ }^{8}$ show that the boundaries and the structure of the field evolved after the 'climatisation' of agriculture.

\section{Incumbents and challengers in the 'clima- tised' modelling field}

The structure of the modelling field is defined by the relative positions of modelling organizations according to the 'capital' (Bourdieu, 2015) of their model. Each model positioned in the field draws its properties from other models, and these relations are conveyed in the formalism of models. There is a consensus on the capital specific of the field, on "what is at stake", and on the 'rules' of the field (Fligstein and McAdam, 2012: 10-11), i.e. modelers agree on a broad definition of what a good model is, and on the ways for a model to improve its value and its position in the field.

Part of this consensus is a recognition of the shortcomings inherent to these models. Modelers recognize that the existing theories are inadequate to describe the complexity of the agricultural and food system at a global scale. They nonetheless have to translate them into models via a set of equations linking the variables that determine global agricultural production (population, eating habits, urbanization, etc.) and global food consumption (yield or production estimates, price elasticities ${ }^{9}$, etc.). Once a representation of agriculture established, data are not always available ${ }^{10}$, and are often of poor quality ${ }^{11}$. Consequently, modelers evaluate models through two channels: (i) the reputation of the model in the academic field, assessed through peer review, (ii) the model's ability to help decision making through quantified scenarios. The modelling field interacts closely with the academic field and the political field, and the capital specific to the modelling field depends on the amount of capital obtained in these two fields: a good model is a model which is deemed both credible and legitimate. Scenario building is the main source of revenue: dominant modelling teams reinvest the profits they make with scenarios in improving their model (by adding a new module for instance), which then helps them find new clients, and thus improve their position in the field. This creates a hierarchy, with models "which received a seal of approval" and "dominate whatever the subject is" (in a modeler's terms) above the others.

The following subsection describes the dynamics of the field since its 'climatisation'. First, integrated models tried to benefit from the new framework to improve their position and to challenge the 'incumbents' of the field, i.e. equilibrium models (Fligstein and McAdam, 2012). Then, other challengers use 'subversion' or 'succession' strategies (Bourdieu, 2015).

\section{Integrated models challenge equilibrium models}

Two models were characterized by interviewees as dominant, stemming from different modelling traditions (equilibrium models vs. integrated models): the IFPRI's IMPACT model, and the Global Biosphere Management Model (GLOBIOM) developed since 2008 by the International Institute for Applied System Analysis (IIASA). The IIASA is a research institute created in 1971 to conduct research on 'world problems' in the context of the Cold War, which became a major research institute in the modelling of climate change (Dahan, 2007). Although they come from different traditions, they both changed to be more relevant to the 'climatized' agenda and now have a similar modular form and both propose a spatialization of their results. IMPACT transformed its partial equilibrium format into a modular structure, and uses agroecological zones. As for GLOBIOM, it relates human activities (food, fiber, energy, industry) with both environmental and economic equilibriums. IMPACT has long dominated the field and still benefits from its "return on investment", in a 
modeler's terms. It has become a reference tool for providing foresight on food security and malnutrition. However, it has been deemed less relevant than GLOBIOM to provide scenarios on the interactions between agriculture, environment, and energy, as it uses a database representing both forests and farming. According to interviewees, IMPACT would be threatened if GLOBIOM were able to improve the way it represents food security:

\section{- You were saying that GLOBIOM is the most dominant model?}

[...] It is a dominant model in terms of publications, and in terms of the issues dealt with: [...] they've got farming, they've got a very good forestry model, etc. [...] GLOBIOM is heavily requested by the European Commission and has been chosen to evaluate everything that has to do with biofuels issues. [...] [But] IMPACT is always the model used to evaluate food security. So GLOBIOM on the issues of food security has not reached that supremacy yet, but given what and how much they publish ... The farming and climate variability issues are blind spots for food security issues and IMPACT does not have that at all. [...] So in a couple of years, GLOBIOM will certainly strongly compete with IMPACT on those issues.

The 'climatisation' of the field has helped challengers compete with incumbents, and GLOBIOM has improved its position in the field, accumulating both scientific and political capital quickly.

\section{Subversion and succession attempts}

Not all models are as successful as GLOBIOM when entering the 'climatised' field. I use Bourdieu's (2015) concepts of 'subversion' and 'succession' to describe their strategies. Some new entrants try to challenge the dominant actors by offering a slightly different definition of what is at stake in the field, i.e. a subversion strategy. For example, French modelling organizations put more emphasis on the analytical power of models and their heuristic use. They see foresight as a way "to construct desired futures and test their consistency and viability" with the help of models, which is typical of the French foresight culture (Dorin and Joly, 2019). Expert knowledge is more important than the model itself, what contrasts with IFPRI's foresight practices, as a French modeler explains:
The idea [with models] is to carry out a "plausibility test" of the scenarios. Basically we do scenarios, then we look at whether they are coherent, whether it works or not. This is something that is done differently from what IFPRI does, where the IMPACT model is really at the centre of the work. Here, let's say, the centre of the work is really all that is done with the experts [who build scenarios] and then we look, we test if the coherence works [with the model] and that's it. IFPRI's scenarios are based more on the results of these models: [...] price evolution, need for investment, etc. is calculated by the IMPACT model, so it is really an approach that is completely different.

This approach is grounded in a definition of economics as a social science, whose predictions could therefore only be considered as insights. Even if decision-makers tend to see modelled scenarios as a 'crystal ball' in the terms of a modeler, French modelers consider that this should be avoided, for instance though a participatory and transparent approach to foresight. This vision is supported by a different model form than dominant models, as in the case of the French model Globagri, which was used in integrated modelling (the Nexus Land-Use (NLU) model) and in scenario building (the Agrimonde foresight). Globagri focuses on world physical food biomass balances (resources, trade, uses), without considering prices. NLU, developed by a French research centre, provides scenarios such as reduction in meat consumption or a balance between undernutrition in the South and over-nutrition in the North, which are not possible with other models. Its simplicity renders NLU transparent for users, and it has easily modifiable parameters: its developers argue that it enables debate with non-specialists. French research centres also used Agribiom (Joly and Dorin, 2019), then Globagri, to develop the Agrimonde foresight, which explores a certain definition of agroecology: (i) change in diet, (ii) reducing food and agricultural waste, (iii) favouring biodiversity and ecological intensification.

As a model's legitimacy depends on its links with other legitimate models (Cornilleau, 2016; Leblond and Trottier, 2016), other new entrants adopt a 'succession' strategy: they try to copy the form used by incumbents or to use some of their data. They also agree with incumbents' definition 
of the capital of the field: they consider modelling as a tool for evidence-based policy-making. These strategies face two difficulties. First, accessing the data, the code, or the modules developed by a dominant model is not easy: they are kept secret as they provide the dominant model with a temporary monopoly on certain topics, and the associated revenues in terms of scenario building. This explains for instance the difficulties faced by a team in their collaboration with IIASA, the goal being to access some of GLOBIOM's modules, as a modeler relates:

They have a strategy, aimed at GLOBIOM. [...] So, well, they try to collaborate. [Sarcastic] They send people who never come back. They try to retrieve bits. Now, they have succeeded, but completely indirectly thanks to [an international expert in modelling]. He succeeded in obtaining data from [...] GLOBIOM livestock modules. So in the end, it ended up at [the team] via a convoluted path.

Another challenge of 'succession' strategies is to identify the added value of a new model as compared to incumbents, in order to generate orders for scenarios that would make the model profitable. The FAO has recruited a well-known modeler in the sub-field of equilibrium models to develop a model, with the hope that it would challenge the supremacy of the IFPRI's model. This modeler explained that the purpose of this project was for FAO to obtain a tool that reflected its "own view":

\section{- So the FAO wanted a model to compete with IFPRI's model?}

That's a very good question; there is a lot of discussion about that. I'm not sure we've resolved it yet, but it's possible that these efforts will eventually merge with the IFPRI's [as they] [...] are very similar. [...] But we've had problems in the past. There are concerns in the FAO that it needs to represent our own view, that it's our scenarios, and that we are not just taking IFPRI scenarios.

Yet the FAO foresight team had little human and financial resources, so the profitability of its new model was all the more pressing. This hostile context made a succession strategy difficult, and the FAO finally decided to merge its project with the IFPRI's model. The FAO is now compelled to com- mission IFPRI (as the previous team using 'succession' does with IIASA) to get scenarios: they are not allowed to develop their "own view" through models, but have outsourced this research.

In this first section, I developed an overview of the dynamics of the field of global agricultural models, showing that all models are not deemed equally credible and legitimate to represent agriculture under climate change. The 'climatisation' of the field generates a competition between equilibrium models (as incumbents) and integrated models (as challengers). New entrants also attempt to replace the incumbent models via subversion or succession. If succession fails, subversion lays the groundwork for a definition of the stake of the field which is different from that of the incumbents, in which models are as much analytical tools for imagining the future as they are evidence-based policy instruments.

\section{Homologies between the modelling field and the field of global governance}

In what follows, I describe how the field of model producers is related to the field of model users. These users are the modelling organizations themselves, but also the stakeholders of the global governance of agriculture (States, NGOs, companies, etc.) which is fragmented between international organizations (United Nations, FAO, World Bank, World Trade Organization (WTO), etc.). I define global governance as "complex, dense, and multidirectional networks" in which governments are influenced by international organizations, research institutes, NGOs, and companies (Djelic and Sahlin-Andersson, 2006). This governance increasingly relies on the use of models: through new institutions, such as sciencepolicy interfaces inspired by the IPCC (Miller, 2007; Haas, 2017), and through new practices, such as the quantification of the performance of international policies (Bezes et al., 2016). In this section, I introduce the concept of 'homology' (Bourdieu, 2015) to account for certain inter-field relations which cannot be captured by Fligstein \& McAdam's 'russian dolls' metaphor. This concept refers to structural parallels between fields because of their relative autonomy, for example between the 
field of art producers and the field of art consumers, or between the field of higher education and the field of power (Bourdieu, 2015). In this line, I show that there is a homology between the field of model producers and the field of model users: users of legitimate models are more likely to have powerful positions in the field of global governance than the users of dominated models, what I show through two examples.

First, I investigate the competition between models as homologous with the competition between participants in a science-policy interface launched in 2002 by the World Bank and the FAO: the International Assessment of Agricultural Science and Technology (IAASTD), which has an intergovernmental and multi-stakeholder format. Then, I consider these homologies through the use of models as indicators for international policymaking, through the cases of the United Nations Sustainable Development Goals (SDGs) and the design and evaluation of agricultural policies for Africa by international organizations. Previous research on science-policy interfaces has emphasized the 'mutual construction' of a modelling type and the associated political field (Shackley and Wynne, 1995). What I show here, however, is the interest of describing the struggles between different models within science-policy interfaces or evidence-based policy making. The concept of homology allows to look at the co-construction of a plurality of competing models with a global governance, which is both complex and multisited and riddled with tensions between diplomacies and other stakeholders.

\section{The politics of modelling in science-policy interfaces: No model, no voice}

To give a sense of how these homologies are revealed in science-policy interfaces, I consider the role of the IFPRI's IMPACT model in the IAASTD process, and how it laid the groundwork for the French Agribiom model described in the previous section. The IAASTD was initially asked to reflect on the possible futures for agriculture on the basis of scenarios created with IMPACT. Doing so, the IASSTD Advisory Committee capitalised on the excellent academic reputation of the IMPACT model and also followed science-policy interfaces, such as the Millenium Ecological Assess- ment (MEA) and the IPCC, which used IMPACT to represent world agriculture. Yet the multi-stakeholder format of the IAASTD led to a debate on scenario making, and several authors disagreed with the weight given to economic models and/ or with the choice of this specific model. Resistance was encountered from certain NGOs represented in the IAASTD, who accused models of being an elitist tool. They argued that models are hardly transparent for those without economics training and that they therefore do not facilitate inclusive deliberations on the future of agriculture (Scoones, 2009). Being based on neo-classical economics, the IMPACT model was also rejected by economists from other traditions. A participant recounts the criticism that a modeler from the IFPRI received during his presentation of the first version of IMPACT-based scenarios:

\footnotetext{
So they began with a General Assembly [...] and there were reactions [from authors] in the room, they said:'no, but wait, the parameters you choose for your models'. Models have been criticized as being econometric models by that kind of heterogeneous group, with native peoples, farmers from Zimbabwe, neo-institutionalist economic researchers. Everyone had something to say, because everyone could speak, I mean, you've just got to raise your hand and say what you want to say. So they took a beating!
}

In the end, the IMPACT model was not used to prepare the scenarios of the IAASTD, which became mostly qualitative. The IFPRI decried this defeat, as a failure to demonstrate the relevance of the IMPACT model. The two sponsors of the IAASTD also joined in this disappointment: the World Bank and the FAO, who develop and promote similar equilibrium models. Company representatives likewise attacked the scientific validity of this assessment, because of the absence of modelled scenarios and of their perception of an overrepresentation of the social sciences, at the expense of mainstream economics and agricultural sciences. This was the case of Syngenta; whose representative wrote an article on IAASTD in NewScientist. com. The IAASTD has been weakened by these attacks: despite its "business as usual is not an option" motto, and its recommendations to consider agroecology and food sovereignty, it had 
less political impact than previous assessments using incumbent models (the MEA or the IPCC).

After their participation in the IAASTD, some actors were motivated to enter the modelling field. This was the case of French research institutes, whose experts have had the impression of being left out because their institution had not developed a model. Models structured the debate to such an extent that it seemed impossible for experts to "have a say" without referring to a model, hence the French disarray:

We had French participants in the chapters on scenarios. [...] [A French author] came back completely miserable saying: "well, we can't say anything; the IFPRI has a say in it, the Indians, the Dutch, their model this, their model that, but we didn't have a say in it, I won't go back to that group, [...] I won't be the one who hasn't got anything to say". It was after that that we launched Agrimonde, even though we knew we wouldn't have Agrimonde ready in time for the IAASTD, but, at least, the next time we would be in the game, we would have our say.

On this basis, French institutes decided to develop their own model (Agribiom), which would be the basis of the first Agrimonde foresight. The second version of Agrimonde, based on the Globagri model, associated NGOs (OXFAM) and social movements (The International Planning Committee for Food Sovereignty), who believed it could be an advocacy tool for agroecology. This example shows that scientific controversies on agriculture, which are debated within science-policy interfaces such as the IAASTD or the IPCC, are both reflected in and reinforced by the struggles in the field of agricultural models.

\section{Models as indicators: Unequal access to evidence-based policy making}

Models are instrumental in science-policy interfaces, as foresight is the basis of their policy recommendations. But economic models are also increasingly being used as indicators to develop evidence-based policies and to quantify the performance of policy-making, as it has been shown for example in healthcare (Sjögren and Helgesson, 2007). Agriculture is no exception, especially at the international level. International organizations involved in the global governance of agriculture claim to develop evidence-based public policies, i.e. using data to target measurable objectives, define policy options, and evaluate public policies. Although United Nations (UN) agencies have always used data to demonstrate the effectiveness of their programmes to convince donors, this trend has increased since the launch of the Millennium Development Goals (MDGs) in 2000. These 'goals' are used by international organizations to quantify the performance of development policies, to harmonize their actions through a common framework, and to make funding allocation decisions. The MDGs have been seen as evidence of a shift toward a "new public management" of the UN (Bezes et al., 2016). Previously, since the late 1980s, the World Bank, which has always invested heavily in evaluation (Goldman, 2005), has recommended using economic equilibrium models as instruments for ex ante or ex post evaluation in various areas, including agriculture and food security (Dervis et al., 1989).

The IMPACT model was used to assess progress toward the Millennium Development Goal of reducing hunger. The dynamics of the modelling field, i.e. the fact that GLOBIOM challenged IMPACT had an impact on the respective roles of their modelling organizations in making these performance indicators. IIASA invested in the new UN agenda with GLOBIOM, through the preparation of the Sustainable Development Goals (SDGs), a set of 169 indicators meant as a successor to the MDGs for the post-2015 agenda. Unlike the MDGs, the SDGs highlight the links between overconsumption in the North and poverty in the South and examine the interactions between the environment, energy, climate change, and food security (Figure 1). On these two issues, GLOBIOM was deemed better able than IMPACT to assess possible interactions and trade-offs, due to its integrated modelling tradition.

Equilibrium models close to IMPACT are also used to define goals and to evaluate the renewed framework of African agricultural policies, in the context of the Comprehensive Africa Agriculture Development Programme (CAADP), prepared by the African Union with technical support from the United Nations and the World Bank. The CAADP encourages foreign investment, through the 
preparation of investment projects at the country level and legislative changes (e.g. biotechnology regulations or free trade). Models intervene in the three steps of policy design within the CAADP: 1) analysis of investment projects, 2) evaluation of agricultural legislation and approval of an investment plan, and 3) evaluation of programme implementation. The instrumental role given to models in the evaluation made it so that the IFPRI, which benefited from the legitimacy of the IMPACT model, took the role that might have been expected the FAO in its work with the CAADP.

The competition between the IFPRI/IIASA in the MDGs/SDGs and the FAO/IFPRI in the CAADP show that using a dominant model is a better guarantee for an institution to shape evidencebased policy-making. This result reinforces what happens in science-policy interfaces: institutions relying on a legitimate model are more likely to be well positioned in the field of global governance. The modelling field and the field of global governance are homologous.

\section{Magicians at work: Shaping the field through standardization}

Is the alignment between the modelling field and the field of global governance simply 'magic' (Roueff, 2013)? This would be the Bourdieusian reading of the homologies that I described in the previous section, which denies any underlying intentionality. Yet fieldwork shows that some modelers seek to strategically produce homologies. This section describes these 'magicians' at work, i.e. the efforts of modelers to have their models used in the field of global governance. In this respect, I show the decisive role of an intercomparison research project, the AgMIP. This project was founded in 2008 on the impetus of crop modelers from the NASAGoddard Institute for Space Studies at Columbia University (which still leads the project), with the support of incumbents in the field of economic models. This alliance of prominent institutions convinced prestigious American universities such as Washington University, national and international agronomic research organizations (CGIAR etc.), governments (United Kingdom, USA, European Commission), and companies (Monsanto) to provide funding and in-kind support. The AgMIP aims to connect three types of models: economic models, climate models, and newly developed global crop models, through the collaboration of three dedicated modelling teams (Global Economics, Crop, and Climate teams) (Figure 2). The economic models presented in the previous sections are part of the Global Economics team. What is at stake within the AgMIP is to propose scenarios on global food security which can localize the impacts of climate change on crops and calculate the related economic risks. Through these scenarios, investors and policymakers can prepare themselves for such futures ${ }^{12}$, for example by buying "climate-smart" biological or financial technologies. Another related goal of the AgMIP is to

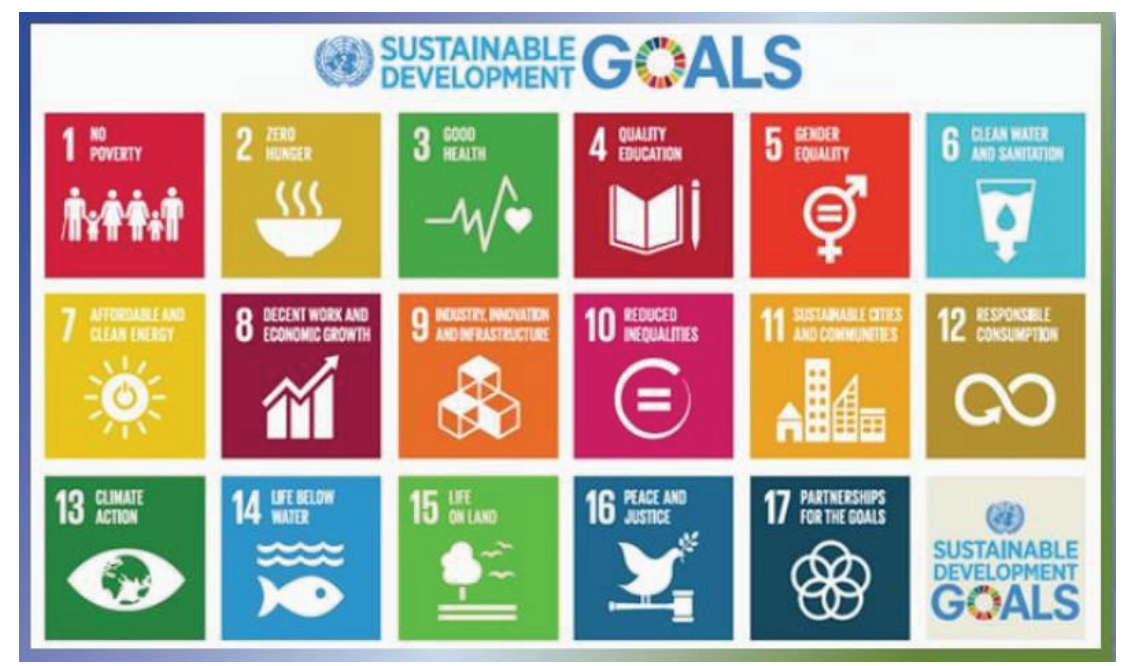

Figure 1: The United Nations Sustainable Development Goals. Source: http://www.un.org/sustainabledevelopment/news/communications-material/ 
compare the models of each type amongst themselves - including the economic models, on which I focus here - to explore the impacts of their differences on foresights, and to try to reduce their heterogeneity in order to build foresights that are as consensual as possible.

In this section, I explain first how the AgMIP was conceived and created by modelers as a decisive tool for producing homologies. Then, I show how the AgMIP, by promoting a standardization of models, shapes the modelling field according to the interests of the 'institutional entrepreneurs' (Fligstein, McAdam, 2012) who have accompanied, and benefited from, the 'climatisation' of the field: it solves the conflict IMPACT vs. GLOBIOM, and it discourages models using subversion strategies.

\section{Producing homologies: From social skills to institutional entrepreneurship}

In the neo-institutionalist perspective, all actors are skilled, yet "resources [...] matter a lot, [such as] the ability to deploy money, connections to the government" (Fligstein and McAdam, 2012: 181). Interviews with modelers show that they make use of such resources such as the head of the Foresight Team of an international organization who developed equilibrium models for many international organizations (OECD, World Bank, FAO), i.e. a well-endowed team directly connected with governance. These resources helped this actor to have his models mobilized as mediators ("we were in the middle", he explains) of policy-decisions. Most revealingly, he presents the milestones of his career through a list of the international policies that he quantified and evaluated with his models, from trade negotiations to climate policies and the Millennium Development Goals:
I was in the OECD for ten years at the beginning of my career. And one of the big studies I worked on initially [...] [was] a study of OECD agricultural policies, so the different subsidies and protection measures that were in place in the late 1980s, which was at the time a very contentious issue among the high-income countries, [...] the United States and the European Commission. So, we were in the middle, trying to assess what were the economic impacts of this. [...] I did a lot of work on the [WTO] Uruguay Round and an assessment of the Uruguay Round. [...] And then I switched to working on climate change, in the mid-1990s. [...] When I was at the World Bank I did a lot of projections for the MDGs.

\section{AgMIP Teams, Linkages, and Outcomes}

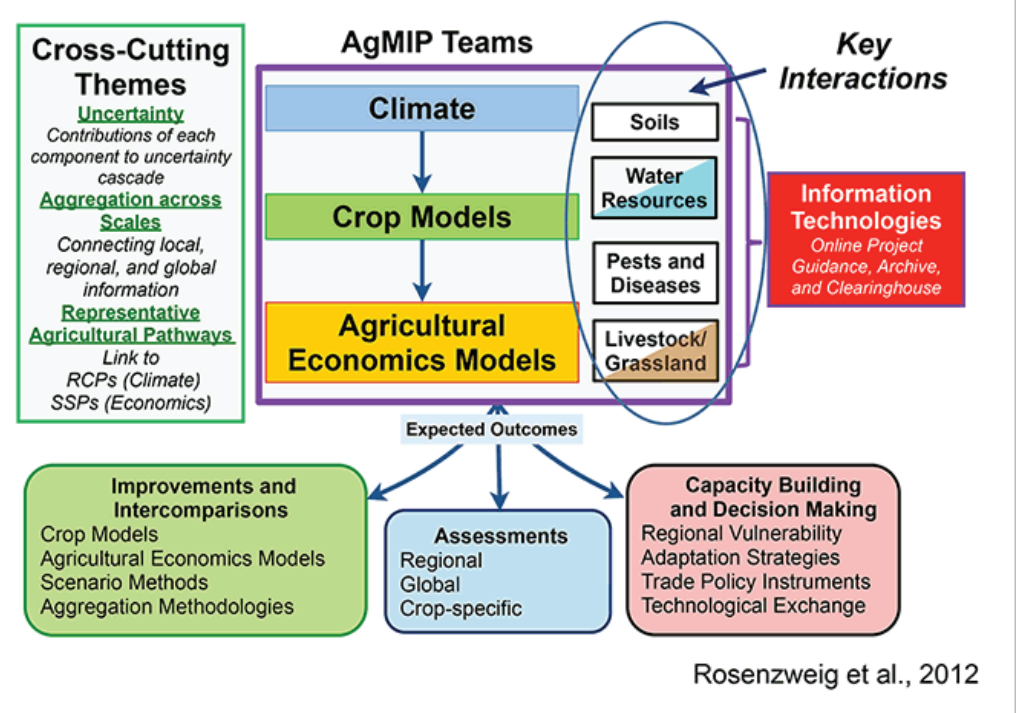

Figure 2: The collaboration between AgMIP's three teams (Agricultural Economics, Crop, Climate) and their expected outputs: improvements and intercomparisons of each type of models; assessments and decision making/capacity building. Source: www.agmip.org 
Later in the interview, this actor explained that he had long wanted to create an intercomparison project of agricultural models, as he believed it would facilitate the circulation of model results in international policies and expertise. He hoped to replicate what he presented as the "success" of the intercomparison of climate models within the Energy Modelling Forum (EMF) ${ }^{13}$ created in the 1970s during the energy crisis. Indeed, most of the research conducted within the EMF, and the resulting changes in the climate models, have informed the IPCC. Even before the AgMIP was created, this modeler imagined the benefits of a hypothetical "Agricultural Modelling Forum" based on the EMF example:

\section{- Why is your Team interested in the AgMIP?}

[...] EMF started in the 1970s because of the energy crisis. So, it was mainly a gathering of energy modelers [...]. When the energy crisis kind of melted away, well climate change appeared! So, EMF became basically the place where a lot of modelling of climate change occurs; so if you look at the IPCC, the $3^{\text {rd }}$ volume on mitigation, almost all that work comes from the EMF modelling group. It has been incredibly successful, EMF! [...] So, my hope was that we could recreate something like EMF but for agriculture, that I actually called "AMF" for "Agriculture Modelling Forum" but right now we are in AgMIP, which is fine. [...]

\section{- As the EMF was largely used in the IPCC, your objective [with AgMIP] is also to be more influential in global assessments? Sure. We'll also influence the IPCC, especially volume 2, you know, on impacts, adaptation, etc. and vulnerability and... [...] we'll be cited in the $5^{\text {th }}$ Assessment Report, but I think as this work progresses, you know, I think we'll have more to feed into the volume 2 report.}

\section{- Are there other reports that you will influence? Yes, there are always things coming out, there will be a post-Rio agenda, you know the Beyond the MDG's [i.e. the Sustainable Development Goals]. [...] I'm sure we'll be asked to provide some assessment of the goals.}

This modeler is confident in his ability to produce some of the homologies that we described in the previous section: he hopes to assess the Sustain- able Development Goals, as well as to feed into one of the most influential science-policy interfaces, the IPCC. He was willing to create an intercomparison device such as the AgMIP, as he was convinced that it would be a decisive instrument for this purpose.

Hence, putting intercomparison at the service of homology production has been a conscious strategy for some modelers. However, the AgMIP only appeared in 2008. The 'climatisation' of agriculture made economic and crop modelers focus on the necessity of creating the AgMIP and constituted an opportunity for them to behave as institutional entrepreneurs, i.e. to try and shape the field according to their interests through "new identities, coalitions and hierarchies" (Fligstein and McAdam, 2012: 84). This is consistent with Fligstein and McAdam's (2012: 181) hypothesis: "entrepreneurs appear not in settled social fields but in those that are emerging or those that are on the verge of transformation". The new framework of climatised agriculture was used by crop modelers to tout the merits of their global crop models, in alliance with economic modelers who had an interest in producing spatialized scenarios. They planned to feed into the 5th Assessment Report of the IPCC and the making of development indicators. More generally, the AgMIP was driven by the preparation of scenarios for the conferences, programmes, etc. of the 'climatised' agricultural agenda. As an interstitial organization at the crossroads between the modelling field and the field of global governance, the AgMIP has enabled these actors to produce homologies between these two fields.

\section{Shaping the field through standardization}

Not only was the AgMIP intended to help modelers circulate their results in the field of expertise and governance, but it also favoured certain actors in the modelling field. This was achieved through the definition of a given objective and certain rules for AgMIP, from which dominant modelers would benefit more than other modelling teams. The AgMIP has organized the preference for certain types of models with the alleged objective of harmonizing them, as other interstitial organizations do, for example in the case of analysis techniques used in the regulation of risks (Demortain, 
2011). The AgMIP aimed at reducing the diversity of models' outputs before these instruments are used by experts and decisionmakers, and this objective has resulted in a certain standardization of the models themselves. However, the AgMIP was not intrinsically intended to shape the field through standardization. There was initially an internal controversy within the group, at the end of which this vision of the AgMIP prevailed.

Harmonizing is a founding principle of the AgMIP (Rosenzweig et al., 2013), which seeks to answer the question: "why do global long-term scenarios for agriculture differ?" (Lampe et al., 2014). Participants in the Global Economics Team of the AgMIP, whatever their position in the modelling field, agree that such an objective is needed in order for models to seem credible. This harmonization is justified in their eyes by the need to protect modelers from criticism that would emerge from greater heterogeneity between models, in the aftermath of the controversy on climate model reliability, following the publication of the $4^{\text {th }}$ Report of the IPCC. As a modeler explains, what is at stake is to build a "robust decision" on science:

When you have results with very strong heterogeneities [between models], in the end you can't do anything with them. [...] In the previous IPCC results, we finally said: "well, you can have a warming between 2 degrees, or even 0.5 degree and 8 degrees"! When we come to the decisionmaker with that kind of conclusion, well, we didn't say anything! So there is a need to reduce the heterogeneity of the models, so all these intercomparison exercises have the ultimate will to reduce the heterogeneity of the models to finally reach a robust decision.

To achieve this harmonization objective, the AgMIP tests the predictions of the different models of the Global Economics Team using the baselines of the IPCC - both its climate scenarios called Representative Concentration Pathways (RCPs) and its socio-economic scenarios, called Shared Socio-economic Pathways (SSPs). Through this lens, various economic global agricultural models propose very different results, for instance when one considers the impact of a given RCP scenario on food prices (Lampe et al., 2014). This is due to their specific form, as shown in the first section, but also to the calibration of elasticities, and the choice of hypotheses (e.g. is land supply rigid? How does food consumption evolve when prices rise?). The AgMIP's objective is then to identify as precisely as possible the origin of these differences, to question the choices that led to them, and to suggest changes in the models to limit divergent outcomes. The overall objective of this intercomparison is for the AgMIP to establish agricultural scenarios of reference, called Representative Agricultural Pathways (RAPs) which are intended to be as influential as the IPCC's SSPs and RCPs, and to complement them.

Furthermore, this organization of work, focused on harmonisation and on the making of reference agricultural scenarios, reinforces the structure of the field (Table 1). As we saw in the first section, challengers using subversion strategies value more the heuristic dimension of models over the use of models as evidence-based tools for decision making, which is where incumbents and challengers using 'succession' strategies put more emphasis. For incumbents, the main objective of AgMIP is to have the results of models converge. For example, the IFPRI transformed IMPACT's parameters after participating in the AgMIP, as one participant explains:

\footnotetext{
IFPRI came out with a report in 2010 [Nelson et al., 2010, which is based on the IMPACT model] [...]: they showed a doubling of food prices by 2050, and then another doubling with climate change. We were very surprised by these results. [...] And actually IFPRI has changed its scenarios very significantly, not based on what we said, but because of the AgMIP process. They were confronted and asked "why do you plan such high prices?" and they answered. Largely the problem was that they used models for kinds of mediumterm analysis and they had pretty low elasticities, while when you think of the long-term, there is much more flexibility. And when they increased their elasticities, food prices came down.
}

A modeler from a less dominant institution in the field considers that participating in AgMIP has challenged the structure of his model, e.g. its number of crops. Upon reflection, however, he did not transform his model, but instead wished to 
preserve what he calls the "good" heterogeneity between models, i.e. the differences in results due to divergent hypotheses that are all equally valid:

\section{- For your model, do you feel that your participation in the AgMIP has made a difference?}

[...] when you are in this community and I come with a very simple representative crop and next to me there is a guy who says "there I have 21 crops", well, I feel a little bad. But you have to resist: everyone has his own questions, his own way of doing things, and it's true that when I came back from an AgMIP meeting, I asked myself, 'you have to break down the model a little more' and then, in retrospect, I said to myself: 'well, no, it doesn't mean anything, considering what we want to achieve, it doesn't mean anything'.

These challengers using subversion strategies have an interest in intercomparison projects, as they could help make their models known through publications and establish contacts with dominant teams. They also seek to situate their model in relation with others and to strengthen their choice of hypotheses and functional forms. They would have preferred that the AgMIP follow the objective of deepening this "technical" comparison of models, precisely in order to avoid standardization. However, this option was not popular among modelers taking part in the project, and it was rejected by the AgMIP's Steering Committee, who focused on harmonizing models and developing scenarios to feed into the IPCC, as a participant recalled:

I arrived after the beginning of a second phase where there was some hesitation regarding which objective to pursue. [...] Meaning when do we really dive into what [one of the coordinators of the Global Economics Team] calls 'deep diving', meaning when do we dive into the model's mechanics, or do we finally ignore all that, and go for politically orientated outcomes, by making scenarios, etc. [...]. There was the influence of the Steering Committee [...] which was going for the Representative Agricultural Pathways, so we eventually went for that.

The overall effect of the AgMIP on the modelling field has been to have helped GLOBIOM challenge
IMPACT, whereas it has kept models using subversion strategies out of the game. Some AgMIP participants consider that the IIASA used the AgMIP as a "launching pad", as GLOBIOM's superiority has been stressed in the publications which came out of the first phase of the AgMIP (Lampe et al., 2014). These publications then became a cornerstone of the IPCC's $5^{\text {th }}$ Assessment Report. IIASA used intercomparison strategically with the GLOBIOM model, producing a new homology between the modelling field and the field of global governance. GLOBIOM, formerly a challenger in the field, has become a new incumbent, partly thanks to AgMIP. This does not mean that all the homologies I documented before arise from the participation of modelling institutions in the AgMIP: not only modelers use more generally their skills for this purpose, but other arenas - such as academic conferences - may have also created standardization between models. Yet, the AgMIP helps us understand recent changes in the field of agricultural models since it was 'climatised', as it reveals certain mechanisms through which the competition between models has been channelled. The construction of an intercomparision between different models resolves the modelling conflict in favour of a new dominant model, and at the same time allows for homology between modelling and politics.

\section{Conclusion}

In this article, I used field theory to analyse the competition between organizations which develop world agricultural models since the 'climatisation' of the global agricultural agenda. I showed a change in the field, with the integrated modelling tradition taking the lead over equilibrium models. Despite this change in its structure, the capital, the stake, and the rules of the field do not change. The dominant models are still those that manage to play to the best of their ability as intermediaries between modelling and politics, i.e. to accumulate both scientific and political capital. Even though GLOBIOM (IIASA) challenged IMPACT (IFPRI), both models are similar in this respect. This specific structure of the modelling field explains the homologies that I documented between the modelling field and the field of 
Table 1: The participation in the AgMIP from two contrasted positions in the modelling field: a challenger using a subversion strategy vs. an incumbent. Source: interviews

\begin{tabular}{|l|l|l|l|l|}
\hline & $\begin{array}{l}\text { AgMIP } \\
\text { experience } \\
\text { / Capacity to } \\
\text { structure the field }\end{array}$ & $\begin{array}{l}\text { Goals for AgMIP / } \\
\text { Definition of what is at } \\
\text { stake in the field }\end{array}$ & $\begin{array}{l}\text { Effects on his own } \\
\text { model / Trajectory in } \\
\text { the field }\end{array}$ & $\begin{array}{l}\text { Expected } \\
\text { relationship with } \\
\text { other models/ } \\
\text { Position in the field }\end{array}$ \\
\hline $\begin{array}{l}\text { Challenger } \\
\text { using a } \\
\text { subversion } \\
\text { strategy }\end{array}$ & $\begin{array}{l}\text { "I don't } \\
\text { understand a } \\
\text { thing"; "There is a } \\
\text { core group we are } \\
\text { not part of" }\end{array}$ & $\begin{array}{l}\text { Having "substantial" } \\
\text { debates through "deep } \\
\text { diving" i.e. comparing } \\
\text { the technical properties } \\
\text { of models }\end{array}$ & $\begin{array}{l}\text { No change, but } \\
\text { clarifying their choices } \\
\text { of hypotheses vis-à-vis } \\
\text { other models }\end{array}$ & $\begin{array}{l}\text { Keep the } \\
\text { "good" scientific } \\
\text { heterogeneity } \\
\text { between models, } \\
\text { while reducing } \\
\text { the "detrimental" } \\
\text { political one }\end{array}$ \\
\hline Incumbent & $\begin{array}{l}\text { "I have wanted to } \\
\text { create the AgMIP } \\
\text { for a long time" }\end{array}$ & $\begin{array}{l}\text { Influence expertise (e.g. } \\
\text { IPCC) and indicators for } \\
\text { evidence-based public } \\
\text { policies (e.g. Sustainable } \\
\text { Development Goals) }\end{array}$ & $\begin{array}{l}\text { New specifications of } \\
\text { models to obtain more } \\
\text { similar outcomes }\end{array}$ & $\begin{array}{l}\text { Distribution of } \\
\text { the topical issues } \\
\text { on the political } \\
\text { agenda according } \\
\text { to the comparative } \\
\text { advantage of each } \\
\text { model }\end{array}$ \\
\hline
\end{tabular}

global governance. I also demonstrated that these homologies are reinforced by the strategies of certain modelers, who behave as institutional entrepreneurs, feeding into the 'climatised' agricultural framework and using the change in the field to improve their positions. Intercomparison projects, such as the AgMIP, are instrumental in this regard: they were created by modelers who had long wanted to have the results of their models more easily circulated in the field of global governance. These actors had an interest in the objectives and rules of the AgMIP, which generated standardization. I explained how these rules helped to solve the main conflict of the field between the two modelling traditions, and at the same time facilitated homologies between modelling and politics. Challengers using subversion, who would have assigned other goals to this intercomparative work, have been marginalized in both the modelling field and in the field of global governance. As suggested by Roueff (2013), homologies are not magic without magicians, i.e. an automatic alignment of positions between the field of model producers and the field of model users. Homologies are rather strategically produced.

This article contributes to the interest of STS in field theory (Berman, 2014; Hess and al., 2017), but it specifically aims to analyse knowledge-power relations in global governance. The co-productionnist research agenda on global governance has often looked at individual given expert committees and how they co-construct their own scientific legitimacy with a political body - such as the IPCC with climate governance (Miller, 2007) or the Codex Alimentarius with the WTO (Winickoff and Bushey, 2010). As global governance is complex, and often multi-level and overlapping, a recent research invites to go beyond a unified vision of 'science' coproducing 'policy' at a global scale, by describing several standards-setting bodies' attempt to earn a form of 'epistemic jurisdiction' 14 (Winickoff and Mondou, 2017). In this line, field theory allows to account for the strategies of a plurality of scientific modelling organizations in the field of global agricultural governance, riddled with conflicting visions and interests. Even if the mathematical form of models suggests that they would be universally valid (Fourcade, 2006), global models are 'situated' and their respective preferences for a given agriculture are not representative of all countries' nor all stakeholders' interests. Despite attempts to standardize the field of models, research organizations using subversion keep developing their models, claiming a right to define agricultural policies, and hoping to become influential in the powerful organizations of the field of governance. Based on this result, further research could consider through the lens of field theory how the stakeholders of global governance struggle through the production and/or use 
of scientific devices (such as models) for the right to define international policies.

\section{Acknowledgements}

This research was supported by a grant from the French National Research Agency for the INNOX project, "Innovation in Expertise. Modelling and simulation as tools of governance" (ANR-13SOIN-0005), coordinated by David Demortain. I am grateful for comments on earlier versions of this article from participants in INNOX workshops, especially from Stefan Aykut, Bilel Benbouzid, David Demortain, and Bertrand Schmitt. Additionally, advice from Jérôme Aust, Olivier Borraz, Patrick Castel, Pierre-Benoît Joly, Jean-Noël Jouzel, Scott Viallet-Thévenin, and two anonymous reviewers of Science \& Technology Studies greatly improved the paper. I also thank Annelies Fryberger for her excellent language editing. 


\section{References}

Akera A (2007) Constructing a Representation for an Ecology of Knowledge: Methodological Advances in the Integration of Knowledge and its Various Contexts. Social Studies of Science 37(3): 413-441.

Armatte M (2010) La science économique comme ingénierie. Quantification et modélisation. Paris: Presses de l'École des Mines.

Cornilleau L and Joly PB (2014) La Révolution Verte, un instrument de gouvernement de la "faim dans le monde". Une histoire de la recherche agronomique internationale. In: Pestre D (ed) Le Gouvernement des technosciences. Gouverner le progrès et ses dégâts. Paris: La Découverte, pp. 171-201.

Cornilleau L (2016) La modélisation économique globale, une technologie de gouvernement à distance ? Généalogie, circulations et traductions d'un modèle de la sécurité alimentaire globale de l'IFPRI. Revue d'Anthropologie des Connaissances 10(2): 171-196.

Aykut SC, Foyer J and Morena E (2017) Globalising the Climate: Cop21 and the Climatisation of Global Debates. London and New York: Routledge.

Berman EP (2014) Field Theories and the Move toward the Market in US Academic Science. Political Power and Social Theory 27: 193-221.

Bernstein S and Van der Ven H (2017) Best Practices in Global Governance. Review of International Studies 43(3): 534-556.

Bezes P, Chiapello È and Desmarez P (2016) Introduction : la tension savoirs-pouvoirs à l'épreuve du gouvernement par les indicateurs de performance. Sociologie du travail 58(4): 347-369.

Bigo D (2011) Pierre Bourdieu and International Relations: Power of Practices, Practices of Power. International Political Sociology 5 (3): 225-258.

Bourdieu P (2015) Sociologie générale: Cours au Collège de France 1981-1983 (Vol. 1). Paris: Le Seuil.

Bruno I, Didier E and Prévieux J (2014) Statactivisme. Comment lutter avec des nombres. Paris: La Découverte.

Callon M (1986) Éléments pour une sociologie de la traduction : la domestication des coquilles Saint-Jacques et des marins-pêcheurs dans la baie de Saint-Brieuc. L'Année sociologique 36: 169-208.

Dahan A (2007) Les modèles du futur. Paris: La Découverte.

Demortain D (2011) Scientists and the Regulation of Risks: Standardising Control. Cheltenham: Edward Elgar.

Dervis K, De Melo J and Robinson S (1989) General equilibrium models for development policies, World Bank: Washington DC.

Desrosières A (2008) L'argument statistique. Tomes / et Il. Paris: Presses des Mines.

Djelic ML and Sahlin-Andersson K (2006) Transnational Governance. Institutional Dynamics of Regulation. Cambridge: Cambridge University Press.

Fligstein N and McAdam D (2012) A theory of fields. Oxford: Oxford University Press.

Fouilleux E (2000) Entre production et institutionnalisation des idées : la réforme de la politique agricole commune. Revue française de science politique 50(2): 277-305.

Fouilleux E and Loconto A (2017) Voluntary standards, certification, and accreditation in the global organic agriculture field: a tripartite model of techno-politics, Agriculture and Human Values 34: 1-14.

Fourcade M (2006) The Construction of a Global Profession:The Transnationalization of Economics. American Journal of Sociology, 112(1), pp. 145-194.

Frickel S and Moore K (2006) The New Political Sociology of Science. Institutions, Networks and Power. Madison: The University of Wisconsin Press. 
Go J and Krause M (2016) Fielding Transnationalism: An Introduction. The Sociological Review Monographs 64: 6-30.

Goldman M (2005) Imperial Nature. The World Bank and Struggles for Social Justice in the Age of Globalization. New Heaven: Yale University Press.

Haas PM (2017) Coupling science to governance: straddling the science-policy interface. In : Littoz-Monnet A (ed) The politics of expertise in international organizations: how international bureaucracies produce and mobilize knowledge, Abingdom \& New York: Routledge, pp.54-75.

Henriksen LF (2013) Economic models as devices of policy change: Policy paradigms, paradigm shift, and performativity. Regulation \& Governance 7(4): 481-495.

Hess DJ, Amir S, Frickel S, Kleinman DL, Moore K and Williams LDA (2017) Structural Inequality and the Politics of Science and Technology. In: Felt U (ed) The Handbook of Science and Technology Studies. Fourth Edition. Cambridge, MA: The MIT Press, pp. 319-346.

Jasanoff S (2004) States of Knowledge: the co-production of science and the social order. London and New York: Routledge.

Joly PB and Dorin B (2019) Modelling World Agriculture as a Learning Machine? From mainstream models to Agribiom 1.0, Land Use Policy, March.

Joly PB and Lacombe P (2017) Sciences sociales et politiques agricoles. Une analyse socio-historique des rapports savoir/pouvoir. Histoire de la recherche contemporaine VI (2) : 163-179.

Kieken H (2004) RAINS : Modéliser les pollutions atmosphériques pour la négociation internationale. Revue d'histoire des sciences 57(2): 377-406.

Kurunmäki L, Mennicken A and Miller P (2016) Quantifying, Economising, and Marketising : Democratising the social sphere? Sociologie du travail 58 : 390-402.

Lampe M, Willenbockel D, Ahammad H et al. (2014) Why do global long-term scenarios for agriculture differ? An overview of the AgMIP global economic model intercomparison. Agricultural Economics 45(1): 3-20.

Leblond N and Trottier J (2016) Performing an Invisibility Spell: Global Models, Food Regimes and Smallholders. International Journal of Sociology of Agriculture \& Food 23(1): 21-40.

Martin JL (2003) What is field theory? American Journal of Sociology 109(1): 1-49.

McKenzie D (2006) An Engine, Not a Camera. How Financial Models Shape Markets. London \& Cambridge: The MIT Press.

Merry SE (2016) The Seduction of Quantification. Measuring Human Rights, Gender Violence, and Sex Trafficking. Chicago: The University of Chicago Press.

Miller CA (2007) Democratization, International Knowledge Institutions, and Global Governance. Governance 20(2): 325-357.

Morgan MS and Morrison M (1999) Models as Mediators. Perspectives on Natural and Social Sciences. Cambridge: Cambridge University Press.

Nelson G, Rosegrant, MW, Palazzo A et al. (2010) Food Security, Farming and Climate Change to 2050. Scenarios, Results, Policy Options. Washington DC: IFPRI.

Paradeise C and Filliatreau G (2016) The Emergent Action Field of Metrics: From Rankings to Altmetrics. In: Lounsbury M, Popp Berman E and Paradeise C (eds) The University under Pressure. Emerald Group Publishing Limited: Research in the Sociology of Organizations, 46, pp. 87-128.

Reinecke J, Manning S and von Hagen O (2012) The emergence of a standards market: Multiplicity of the sustainability standards in the global coffee industry. Organization Studies 33(5-6): 791-814. 
Rosenzweig C, Jones JW, Hatfield JL et al. (2013) The agricultural model intercomparison and improvement project (AgMIP): protocols and pilot studies. Agricultural and Forest Meteorology 170: 166-182.

Rottenburg R, Merry SE, Park SJ and Mugler J (2015) The World of Indicators. The Making of Governmental Knowledge through Quantification. Cambridge: Cambridge University Press.

Roueff O (2013) Les homologies structurales : une magie sociale sans magiciens ? La place des intermédiaires dans la fabrique des valeurs. In: Coulangeon P and Duval J (eds) Trente Ans Après la Distinction, de Pierre Bourdieu. Paris: La Découverte, pp.153-164.

Shackley and Wynne (1995) Global Climate Change: the Mutual Construction of an Emergent Science-Policy Domain. Science and Public Policy 22(4): 218-230.

Scoones I (2009) The politics of global assessments: the case of the International Assessment of Agricultural Knowledge, Science and Technology for Development (IAASTD). The Journal of Peasant Studies 36(3): 547-571.

Sjögren E and Helgesson CF (2007) Health economics and medicine in the shaping of Swedish markets for subsidized pharmaceuticals. In: Callon M, Millo Y and Muniesa F (eds) Market Devices, Oxford: Blackwell Publishing, pp. 215-240.

Tomlinson I (2013) Doubling Food Production to Feed the Nine Billion: A Critical Perspective on a Key Discourse of Food Security in the UK. Journal of Rural Studies 29: 81-90.

Winickoff DE and Bushey (2010) Science and Power in Global Food Regulation: The Rise of the Codex Alimentarius, Science Technology \& Human Values 35(3): 356-381.

Winickoff DE and Mondou M (2017) The problem of epistemic jurisdiction in global governance: The case of sustainability standards for biofuels, Social Studies of Science 47(1): 7-32.

\section{Notes}

1 Models' outputs - e.g. the 70\% increase in the global food production by 2050 , a result of a FAO model - fuel the productionnist narrative which is instrumental to agrifood industry and export-countries (Tomlinson, 2013).

2 In 2010 the team consisted of the ten following models and institutions: AIM (developed by the NIES/ Japan), ENVISAGE (FAO/World Bank), EPPA (MIT/USA), FARM, (USDA) GTEM (ANTARES/Australia), MAGNET (LEI-WUR, Netherlands), GCAM (PNNL, USA), GLOBIOM (IIASA), IMPACT (IFPRI), MAgPIE (PIK, Germany).

3 They were actually inspired by Bourdieu in this: for him, fields (e.g. the scientific field, the political field, etc.) are specialized subfields of the 'social field' (society), which is not a meta-field, but is a conglomeration of all fields.

4 It refers to a "form of embedding whereby actors that make up smaller collectivities are located within larger strategic action fields that contain larger collectivities" (Fligstein and McAdam, 2012: 59)

5 These institutions developed both computable general equilibrium (CGE) models (representing the whole economy) or partial equilibrium (PE) models (focusing on the dynamics of the agricultural sector).

6 More details are provided by Leblond and Trottier (2016) and by Joly and Lacombe (2017).

7 Four modelling traditions have been working on this difficult task since the 1970s (Leblond and Trottier, 2016): 1) economic models 2) biophysical models, representing global agricultural productivity (potential yields according to agronomic theory; actual yields according to databases), 3) integrated models, 4) hybrid models, which link socio-economic databases to agronomic databases at a pixel scale thanks to satellite-produced datasets. 
8 A last evolution is that both equilibrium and integrated models benefited from the democratization of satellite datasets in the 2000s: "they integrated Geographic Information Systems and began projecting their results onto pixel grids" (Leblond and Trottier, 2016: 7), what enables them to localize even more precisely the agriculture-climate interactions.

9 Price elasticity quantifies the change in demand for a good caused by the change in its price.

10 Databases produced by the FAO or by networks of modelers follow agricultural chains, so mixed or alternate crops encouraged by agroecology cannot be represented, for example.

11 This is due to due to problems commensurating at the international scale a variety of soils, climates, etc., but also because some countries want to keep them secret for trade-related reasons.

12 Source: http://www.agmip.org/feature-video/

13 The EMF is probably the oldest model intercomparison, but there has been a rise in these projects in the context of the controversies on the validity of models used by the IPCC, as can be seen in the InterSectoral Impact Model Intercomparison Project (ISIMIP) on the effects of climate change, or the Integrated Assessment Modelling Consortium (IAMC) on integrated models.

14 This concept refers to "the power to produce or warrant technical knowledge for a given political community, topical arena or geographical territory" (Winickoff and Mondou, 2017: 7).

\section{Appendix 1. List of Acronyms}

AgMIP: Agricultural Models Inter-comparison and Improvement Project

CAADP: Comprehensive Africa Agriculture Development Programme

CGIAR: Consultative Group in International Agricultural Research

EMF: Energy Modelling Forum

FAO: Food and Agriculture Organization

GATT: General Agreement on Tariffs and Trade

GLOBIOM (model): Global Biosphere Management Model

IAASTD: International Assessment of Agricultural Knowledge Science and Technology

IFPRI: International Food Policies Research Institute

IIASA: International Institute for Applied System Analysis

IMPACT (model): International Model for Policy Analysis of Agricultural Commodities and Trade

IPCC: Intergovernmental Panel on Climate Change

MDGs: Millennium Development Goals

MEA: Millennium Ecological Assessment

NLU (model): Nexus-Land Use

OECDE: Organization for Economic Cooperation and Development

SDGs: Sustainable Development Goals

UN: United Nations

WTO: World Trade Organization 